\title{
Preparation and In Vitro and In Vivo Characterization of the Tumor-specific Antigen-derived Peptide as a Potential Candidate for Targeting Human Epidermal Growth Factor Receptor 2-positive Breast Carcinomas
}

\author{
SUBHANI M. OKARVI and IBRAHIM ALJAMMAZ \\ Cyclotron and Radiopharmaceuticals Department, \\ King Faisal Specialist Hospital and Research Centre, Riyadh, Saudi Arabia
}

\begin{abstract}
Background/Aim: The human epidermal growth factor receptor (HER2) is considered as one of the most well-characterized tumor-associated antigens for cancer therapy and plays an important role in the growth and progression of breast cancer. Overexpression of HER2 in various cancers and the availability of its extracellular region makes it a clinically useful target for the development of tumor-antigen specific agents. In this study, we have prepared a HER2-targeted hybrid peptide as a single-photon emission computed tomography (SPECT) imaging probe and evaluated its tumor targeting potential in subcutaneous HER2-positive breast cancer xenograft models. Materials and Methods: The HER2-targeted hybrid peptide was prepared by solid-phase peptide synthesis and radiolabeled with ${ }^{99 m}$ Tc by the ligand exchange method. In vitro tumor cell binding properties of ${ }^{99 m} T c-H E R 2$ were evaluated in HER2-positive (SKBR3) and ER-positive (MCF7 and T47D) breast cancer cell lines. In vivo tumor targeting characteristics were investigated in both SKBR3 (HER2positive) and MDA-MB-231 (HER2-negative) xenografted animal models. Results: A high labeling efficiency of greater than $95 \%$ was achieved when HER2 peptide was radiolabeled with ${ }^{99 m}$ Tc by the standard ligand exchange method. ${ }^{99 m}$ Tc-HER2 displayed a high binding affinity $\left(K_{d}=49.95 \pm 14.11 \mathrm{nM}\right)$ to HER2-positive SKBR3 cell line whereas in the case of the ER-positive cell lines (MCF-7 and T47D), the binding affinity was found to be 2-3-fold lower than SKBR3. In vivo tumor uptake in nude mice with SKBR3
\end{abstract}

Correspondence to: Subhani M. Okarvi, Cyclotron and Radiopharmaceuticals Department, King Faisal Specialist Hospital and Research Centre, P.O. Box 3354, Riyadh 11211, Saudi Arabia. Tel: +966114424812, e-mail: sokarvi@kfshrc.edu.sa

Key Words: HER2, breast cancer, hybrid peptide, tumor-targeting peptide, imaging. tumor xenografts was $2.81 \pm 0.79 \% \mathrm{ID} / \mathrm{g}$ as early as $60 \mathrm{~min}$ p.i. The uptake in SKBR3 tumors was always higher than the uptake in the blood and muscle, with good tumor-to-blood and tumor-to-muscle ratios. In contrast, low accumulation in ER-positive tumors (MCF7 and T47D) was observed compared to HER2-positive SKBR3 tumor mice. A low to moderate (less than $5 \% \mathrm{ID} / \mathrm{g}$ ) accumulation and retention of ${ }^{99 m}$ Tc-HER2 was found in most of the major organs excluding the kidneys in both healthy and tumor-bearing mice. Conclusion: In view of its ability to detect HER2positive breast cancer cells in vivo, ${ }^{99 m}$ Tc-HER2-targeted peptide may be a promising tumor imaging probe and warrants further investigation.

The human epidermal growth factor receptor (HER2) is the most studied tumor-associated antigen in breast cancer (1, $2)$. This receptor tyrosine kinase is part of the epidermal growth factor receptor (EGFR) family and is overexpressed in many cancers, such as breast, ovarian, endometrial, gastric, pancreatic, and prostate cancer. Particularly in breast cancer, HER 2 is overexpressed in about $30 \%$ of primary and metastatic breast cancers, and about $90 \%$ of all breast cancers express HER2 to some extent. This overexpression can result in up to 200 -fold increase in the concentration of HER2 in tumor versus normal tissues. Amplification/ overexpression of HER2 in breast cancers is classified as HER2-positive breast cancers, which is one of the most aggressive forms of breast cancer since a high level of HER2 expression in breast cancer correlates with drug resistance, a higher tumor growth rate, high metastatic potential, and poor long-term patient survival rate (3-5). This suggests that HER2 overexpression may be an important tumor initiating event in breast cancer and that the overexpressed receptors promote the growth and spread of cancer cells (6). The high HER2 expression in many cancers and the availability of its extracellular region as a useful target for non-invasive detection of HER2-expressing tumors can provide a useful 
insight for better patient management and create great clinical interest in developing HER2-specific agents.

Over the past few years, several monoclonal antibodies and tyrosine kinase inhibitors have been investigated for targeting HER2-expressing tumors (7-9). Trastuzumab (herceptin), a humanized recombinant monoclonal antibody, which binds to the extracellular region of HER2, was developed and approved by the FDA (U.S. Food and Drug Administration) for the treatment of HER2-positive cancer patients. Treatment outcome was found to be more beneficial when trastuzumab was used in combination with other drugs or after standard chemotherapy; and prognosis was improved in patients with metastatic HER2-positive cancer after trastuzumab treatment. However, patients with low and/or heterogeneous HER2 expression have shown a poor response to trastuzumab treatment; determination of HER2 status is, therefore, essential in selecting patients that would benefit from HER2-targeted therapy (5, 9-12). Molecular imaging especially "image and treat" is an attractive approach for achieving this task however, the use of full size monoclonal antibodies, such as trastuzumab for diagnostic imaging is not ideal because of their long retention in blood. Thus, a rapid and more efficient noninvasive method for the assessment of HER2 tumor expression is needed in nuclear oncology (5).

The use of radionuclide molecular imaging would enable detection of HER2 tumor expression by a noninvasive procedure in both primary and advanced tumors, without false-negative results due to biopsy sampling errors. Clinical utility of radionuclide imaging of HER2 expression using ${ }^{111}$ In-DTPA-trastuzumab allows the identification of patients responding to trastuzumab treatment and patients who may suffer from toxicity associated with such treatment (12). In many studies, ${ }^{111}$ In-DTPA-trastuzumab has shown high accumulation in tumor lesions (13); however, because of high background activity the optimal time of antibody-based imaging was $\sim 72 \mathrm{~h}$ after the administration of radioantibody which somewhat limits its clinical efficiency (14-16). Consequently, attention has been focused towards the development of smaller HER2-specific targeting agents, such as peptides because of their rapid pharmacokinetics (i.e. rapid clearance from the blood and nontarget tissues) thus allowing imaging within an hour after the injection of the peptide, radiopharmaceutically making them more suitable for clinical imaging procedures $(3,17,18)$.

The advancement of peptide phage display has facilitated the discovery of a variety of tumor targeting peptides against a wide range of tumor types. Numerous high affinity tumor target-specific peptides have been discovered through phage display (16). One such hexapeptide, Lys-Cys-Cys-Tyr-SerLeu, which bound the extracellular domain of human HER2, has shown the potential for targeting HER2-positive human breast and prostate cancers $(19,20)$. Nonetheless, this method is not optimal in terms of tumor targeting and its pharmacokinetic properties and requires improvement (16, 20). Another HER 2 targeted peptide that was selected based on the E75 [369-377] sequence of the HER2 protein has been shown to be overexpressed in many breast cancer patients. The E75 [Lys-Ile-Phe-Gly-Ser-Leu-Ala-Phe-Leu; HER2, 369-377] sequence derived from HER2 protein's extracellular region also has been employed in the formulation of a peptide-based cancer vaccine (nelipepimutS) to prevent breast cancer recurrence in high-risk patients $(1,4,21)$. It seems logical to assume that this key sequence can be used to design a HER2-based peptide for targeting HER2-positive breast cancer. Although no prior information is available about the receptor affinity of this tumor-antigen derived peptide for HER2-positive breast cancer, there was an interest to investigate the tumor targeting potential of this HER2-derived peptide.

The main aim of this study was to construct a potent HER2-targeted peptide as a single-photon emission computed tomography (SPECT) imaging probe by combining the key amino acid sequences of the two important HER2 peptides and evaluate its tumor targeting potential in vivo in HER2positive human breast cancer xenograft models. The HER2 hybrid peptide was prepared by solid-phase peptide synthesis and radiolabeled with technetium-99m $\left({ }^{99 \mathrm{~m}} \mathrm{Tc}\right) .{ }^{99 \mathrm{~m}} \mathrm{Tc}$ is a preferred radionuclide for radiolabeling tumor targeting peptides due to its wide availability, suitable half-life $(6 \mathrm{~h})$, and ideal $\gamma$-energy (140 keV) for medical diagnostic imaging (18). We present herein the synthesis, radiolabeling, and preclinical in vitro and in vivo characterization of a new HER2 peptide for the detection of HER2-positive breast cancer in vivo.

\section{Materials and Methods}

General. All standard reagents, solvents and Fmoc-amino acids for the peptide synthesis were purchased from commercial sources and used as received. ${ }^{99 \mathrm{~m}} \mathrm{Tc}\left({ }^{9} 9 \mathrm{~m} \mathrm{TcO}_{4}{ }^{-}\right)$was obtained from a ${ }^{99} \mathrm{Mo} /{ }^{99 \mathrm{~m}} \mathrm{Tc}$ generator (Elumatic III, CIS bio international, Cedex, France). The structure of the HER2 peptide was confirmed by mass spectrometry (Waters Micromass Quattro Premier XE, Manchester, UK). Reversed-phase high performance liquid chromatography (RPHPLC) was performed on a Shimadzu HPLC system (Shimadzu Corporation, Kyoto, Japan) equipped with a UV-VIS detector (Shimadzu Corporation, Kyoto, Japan), set at $220 \mathrm{~nm}$, a $\gamma$ radioactivity detection system and the Lauralite chromatogram analysis program (LabLogic Systems Ltd., Sheffield, UK). Radioactive samples from in vitro and in vivo studies were measured using a $\gamma$-counter (Mucha, raytest Isotopenmessgeräte $\mathrm{GmbH}$, Straubenhardt, Germany).

Preparation of HER2-derived hybrid peptide. HER2-derived hybrid peptide (Ac-Gly19-Gly ${ }^{18}$-Cys ${ }^{17}$-ALA ${ }^{16}$-Lys ${ }^{15}$-Ile ${ }^{14}-$ Phe $^{13}-$ Gly ${ }^{12}$

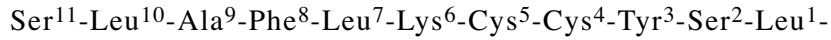
$\mathrm{CONH}_{2}$ ) was synthesized manually by solid-phase peptide synthesis following standard Fmoc (9-fluorenylmethoxycarbonyl) chemistry, 
using Rink amide MBHA (4-methylbenzhydrylamine) resin (100200 mesh) on a $0.1 \mathrm{mmol}$ scale according to a method described previously $(22,23)$. Briefly, the first Fmoc-amino acid (Fmoc-Leu$\mathrm{OH})$ was activated with HBTU ( $O$-benzotriazol-1-yl)-1,1,3,3tetramethyluronium hexafluorophosphate) in the presence of DIEA (diisopropylethylamine) and coupled to the resin. The peptide chain was then elongated in cycles of Fmoc deprotection followed by coupling of the subsequent Fmoc-amino acid to the resin. After stepwise addition of all the desired 19-amino acids to the sequence, the peptide was acetylated at the $N$-terminus with acetic anhydride/triethylamine. The crude peptide was cleaved from the resin by treating with $94 \%$ trifluoroacetic acid (TFA), $1 \%$ triisopropylsilane, $2.5 \%$ 1,2-ethanedithiol, and $2.5 \%$ water. The purity of the peptide was confirmed by HPLC and its structural identity by mass spectrometry.

Radiolabeling with ${ }^{99 m} T c$. A $50 \mu$ sample of the peptide solution (1 $\mathrm{mg} / \mathrm{ml} \mathrm{CH}_{3} \mathrm{CN} / \mathrm{H}_{2} \mathrm{O}$ ) was mixed with $200 \mu \mathrm{l} 0.2 \mathrm{M}$ citrate-phosphate buffer ( $\mathrm{pH}$ 9), $250 \mu \mathrm{l}$ sodium potassium tartrate $(40 \mathrm{mg} / \mathrm{ml}$ aqueous solution) and $20 \mu \mathrm{l} 5 \%$ ascorbic acid. To this, freshly prepared $100 \mu \mathrm{l}$ of $\mathrm{SnCl}_{2}\left(20 \mathrm{mg} \mathrm{SnCl} 2.2 \mathrm{H}_{2} \mathrm{O}\right.$ in $\left.5 \mathrm{ml} 0.05 \mathrm{~N} \mathrm{HCl}\right)$ was added followed

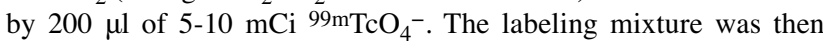
heated at $90^{\circ} \mathrm{C}$ for $10 \mathrm{~min}$ and allowed to cool prior to HPLC analysis

HPLC purification and analysis. The HPLC analysis and purification of the peptide was performed on a Shimadzu HPLC system using Econosphere C18 reversed-phase column $(10 \mu \mathrm{m}, 250 \times 4.6 \mathrm{~mm})$. For HPLC experiments, a gradient solvent system of $0.1 \%$ (v/v) TFA in $\mathrm{H}_{2} \mathrm{O}$ (solvent A) and $0.1 \%$ (v/v) TFA in $\mathrm{CH}_{3} \mathrm{CN}$ (solvent B) at a flow rate of $1.1 \mathrm{ml} / \mathrm{min}$ was used (22). The main peak of the radiopeptide was isolated and reconstituted in sterile saline for in vitro and in vivo experiments.

In vitro stability in plasma. The HPLC-purified radiopeptide (100 $\mu \mathrm{l})$ was incubated with human plasma $(500 \mu \mathrm{l})$ in duplicate at $37^{\circ} \mathrm{C}$ for up to $4 \mathrm{~h}$. Following incubation at 1 and $4 \mathrm{~h}$, the plasma proteins were precipitated with a mixture of $\mathrm{CH}_{3} \mathrm{CN} / \mathrm{EtOH}(1: 1 \mathrm{v} / \mathrm{v}, 400 \mu \mathrm{l})$ and the sample was centrifuged $(7,000 \mathrm{rpm}, 7 \mathrm{~min})$. The supernatant layer was removed, filtered through Millex GP filter $(0.22 \mu \mathrm{m})$, and analyzed by radio-HPLC under the conditions described above in order to determine the proteolytic stability of the $99 \mathrm{mTc}-\mathrm{HER} 2$.

In vitro tumor cell binding and internalization. The cell-binding and subsequent internalization of $99 \mathrm{~m}$ Tc-HER2 peptide into HER2positive SKBR3 and ER-positive MCF7 and T47D breast cancer cell lines $(2,10,24,25)$ [American Type Culture Collection, Rockville, MD, USA] was performed according to the method described previously (22). In addition, cell binding was conducted on HER2-negative MDA-MB-231 breast cancer cell line $(14,25)$ to further confirm the receptor specificity of $99 \mathrm{mTc}-\mathrm{HER} 2$. The binding data were analyzed by a nonlinear regression analysis program (GraphPad Software Inc., San Diego, CA, USA). In order to differentiate between cell-surface bound and cellular internalized radioactivity, cell pellet was treated with $300 \mu$ of acidic buffer $(0.02 \mathrm{M}$ sodium acetate in saline, $\mathrm{pH} 5.0)$ for $10 \mathrm{~min}$ at $37^{\circ} \mathrm{C}$ at the end of the binding experiment, followed by centrifugation and washing with cold acidic buffer. The amount of cell surface-bound (acid-wash) and internalized (acid-resistant) radioactivity was determined by measuring the radioactivity of the supernatant and the cell-pellet, respectively, in a $\gamma$-counter.
In vivo animal biodistribution. Approval for the animal protocol used in this study was obtained from the Institutional Animal Care and Use Committee. Animal studies were conducted according to the international regulations governing the safe and proper use of laboratory animals (26). In vivo biodistribution was performed on healthy Balb/c mice ( $\mathrm{n}=3-5$ in each group, body mass $19-22 \mathrm{~g}$ ) at 1 and $4 \mathrm{~h}$ after $i . v$. injection of the HPLC-purified radioligand ( $100 \mu \mathrm{l}$, $10-15 \mu \mathrm{Ci}$, total peptide dose $\sim \mu \mathrm{g}$ ) via the lateral tail vein as described previously (22). Uptake of radioactivity in the tissues and organs was expressed as the percent injected dose per gram $(\% \mathrm{ID} / \mathrm{g})$ of tissue/organ, which was calculated by comparison with standard solutions representing $10 \%$ of the injected dose per animal. For the clearance studies, radioactivity in the collected urine (100-200 $\mu \mathrm{l})$ was measured and expressed as the percent of the injected dose per organ (\% ID/tissue).

In vivo tumor targeting and gamma camera imaging. HER2-positive SKBR3 breast tumor xenografts in nude mice models were used for in vivo tumor targeting. About 7 million SKBR3 cells were injected subcutaneously into each mouse and allowed to grow for 4-6 weeks. After sufficient growth of tumors, the animals were sacrificed and the uptake of $99 \mathrm{mTc}-\mathrm{HER} 2$ from the tumors and other major organs was determined by $\gamma$-counting. In the $\gamma$-camera imaging study, the mouse was injected with $\sim 200 \mu \mathrm{Ci}$ of $99 \mathrm{mTc}-\mathrm{HER} 2$ through the tail vein. Mouse static planar images were then acquired at $1 \mathrm{~h}$ after the injection by a portable hand-held $\gamma$-camera equipped with $\mathrm{CsI}(\mathrm{Tl})$ scintillation detector, with intrinsic spatial resolution of $2.4 \mathrm{~mm}$ (IP guardian 2, Li-Tech, Italy).

Statistical analysis. Results are expressed as mean \pm S.D. where appropriate. For data comparisons, mean values were compared using the Student's $t$-test (GraphPad Software, Inc., San Diego, CA, USA). A probability value $(p)$ less than 0.05 was considered statistically significant.

\section{Results and Discussion}

High expression of tumor-specific antigens, such as HER2, found on various malignant cells as compared to normal cells provides the basis for successful use of radiolabeled tumorantigens-derived peptide for tumor targeting. One attractive tactic of developing probes for targeting HER2-positive tumors is the use of active peptide sequence derived from such tumor-specific-antigens. One distinctive benefit of such peptides is that they can be easily synthesized chemically and modified molecularly to afford desired pharmacokinetics (15, 23). The most well studied tumor-associated antigen in breast cancer is HER2, which is positive in about $30 \%$ of all human breast cancers (1). The HER2 protein of the epidermal growth factor receptor family plays a key role in aggressive human breast cancer (9). As HER2 is overexpressed at the surface of tumor cells, the accessibility of the receptor target makes it suitable for tumor diagnosis and therapy. Accurate and noninvasive methods for detection of HER2 expression in breast cancer can provide useful diagnostic information with direct impact on patient management (27). The use of radionuclide imaging would enable detection of HER2 by a noninvasive 
procedure in both primary tumors and metastases, without false-negative results due to biopsy sampling errors $(5,27)$. Thus HER2-specific peptides have attracted great clinical attention recently. Here, we present the preparation and evaluation of a new HER2-derived hybrid peptide as a potential SPECT imaging probe for targeting HER2-positive breast cancer.

Synthesis of HER2 peptide conjugate. The HER2 peptide evaluated in this study was conveniently and successfully prepared by solid-phase peptide synthesis according to Fmocchemistry in reasonably good yield $(\sim 40 \%)$. We utilized a well-characterized Cys-Gly-Gly chelating sequence because of its convenience of direct coupling to the peptide molecule during solid-phase peptide synthesis and the ease of radiolabeling with ${ }^{99} \mathrm{~m} \mathrm{Tc}$ (23). Aminolevulinic acid (ALA) residue was chosen as a spacer because of its possible role in breast cancer (28) and inserted between the chelating sequence and the targeting peptide to keep the chelating sequence distant from the binding region. The structural identity of HER2 peptide was confirmed by mass spectrometry: $\left([\mathrm{M}+\mathrm{H}]^{+}\right.$ calculated=2064; $[\mathrm{M}+2 \mathrm{H}]^{2+}$ found=1034).

Radiolabeling with ${ }^{99 m}$ Tc. Radiolabeling of HER2 peptide with ${ }^{99 m}$ Tc was achieved by the ligand exchange method using sodium potassium tartrate as a weak chelating agent. By the exchange labeling approach, the radiolabeling efficiency of ${ }^{99 \mathrm{~m}}$ Tc-HER2 complex was greater than $95 \%$ with a specific radioactivity greater than $250 \mathrm{Ci} / \mathrm{mmol}$. Radio-HPLC analysis revealed the formation of one main peak corresponding to ${ }^{99 \mathrm{~m}}$ Tc-HER2 at $20 \mathrm{~min}$ (Figure 1). Radiochemical purity was determined by evaluating radioactivity peak eluted for ${ }^{99 \mathrm{~m}} \mathrm{Tc}-\mathrm{HER} 2$ from the RPHPLC column and calculating the area under the peak (region of interest). The optimal radiolabeling with ${ }^{99 \mathrm{~m}} \mathrm{Tc}$ was achieved in the presence of $0.2 \mathrm{M}$ citrate phosphate buffer $\mathrm{pH}$ 9. Generally, an alkaline $\mathrm{pH}$ enhances the formation of a complex between triamide thiol Cys-Gly-Gly and ${ }^{99 \mathrm{~m}} \mathrm{Tc}$ by deprotonation of three-amide nitrogens of the N3S type chelating system $(22,23)$. It was found that the ${ }^{99 \mathrm{~m}}$ Tc-HER2 complex remained stable $(>75 \%)$ at room temperature for up to $18 \mathrm{~h}$ post-labeling.

In vitro metabolic stability in plasma. The metabolic stability of ${ }^{99 m}$ Tc-HER2 was studied in human plasma in vitro. Following incubation of ${ }^{99} \mathrm{~m}$ Tc-HER 2 in plasma at 1 and $4 \mathrm{~h}$, the plasma proteins were precipitated with a mixture of acetonitrile/ethanol and the supernatant layer was analyzed by radio-HPLC, using the experimental conditions described above, to test the stability of the radiolabeled peptide in human plasma. The results indicated that up to $80 \%$ radioactivity was remained bound to the radiopeptide after $4 \mathrm{~h}$ incubation, with a slow reformation to free ${ }^{99} \mathrm{TcO}_{4}{ }^{-}$(up to $20 \%$ ), indicating a reasonably high proteolytic stability and a low binding to plasma proteins of the ${ }^{99 \mathrm{~m}}$ Tc-HER2. The percent of peptide that remained intact in the plasma was $89 \%$ at $1 \mathrm{~h}$, and $80 \%$ at $4 \mathrm{~h}$, signifying a low enzymatic degradation of ${ }^{99 \mathrm{~m}}$ Tc-HER2 by plasma proteases. The high metabolic stability is in agreement with the high radiochemical stability obtained for ${ }^{99} \mathrm{~m}$ Tc-HER2, suggesting a good correlation between the two. It is generally believed that the high metabolic stability of a radiopeptide in human plasma is important for tumor targeting, as the radiolabeled peptide has to reach the desired target intact to exert a maximum effect.

In vitro tumor cell binding and cellular internalization. In view of the variable degrees of HER2 expression found in different human breast cancer cell lines $(2,5,24,29)$, it is reasonable to explore the binding ability of ${ }^{99 \mathrm{~m}} \mathrm{Tc}-\mathrm{HER} 2$ peptide not only on the HER2-positive and estrogen receptor (ER) independent SKBR3 breast cancer cell line, but also on the ER-positive MCF7 and T47D breast cancer cell lines, which show low to moderate expression of HER2 $(10,29)$. The binding affinity $\left(K_{\mathrm{d}}\right)$ of ${ }^{99 \mathrm{~m}} \mathrm{Tc}-\mathrm{HER} 2$ to the respective breast cancer cell lines was determined by saturation binding assays. In addition, the maximum number of binding sites $\left(B_{\max }\right)$ was estimated (GraphPad Software Inc., San Diego, CA, USA).

The cell binding data (Table I) showed that $99 \mathrm{~m}$ Tc-HER2 displayed a high binding affinity to HER2-positive SKBR3 breast cancer cell line $\left(K_{\mathrm{d}}=49.95 \pm 14.11 \mathrm{nM}\right)$. However, in the case of ER-positive breast cancer cell lines (MCF7 and T47D), ${ }^{99} \mathrm{~m}$ Tc-HER 2 exhibited a significantly lower binding affinity, with $K_{\mathrm{d}}$ values of $157.29 \pm 24.56 \mathrm{nM}, p=0.002$, and $169.11 \pm 22.09 \mathrm{nM}, p=0.001$, respectively. These results demonstrate that the binding affinity of $99 \mathrm{~m}$ Tc-HER2 was found to be more than 3-times higher for HER2 overexpressing SKBR3 cells than the binding values obtained for lowexpressing HER2-positive and ER-positive MCF7 and T47D cell lines. It is worth mentioning that the binding affinity of ${ }^{99} \mathrm{~m}$ Tc-HER2-derived peptide to SKBR3 cell line was about 6fold higher than the one reported for HER2-targeted peptide (49.95 nM versus $295 \mathrm{nM}$ ) (20). Tumor receptor specificity of ${ }^{99 \mathrm{~m}} \mathrm{Tc}-\mathrm{HER} 2$ was further confirmed by results showing low affinity binding to HER2-negative MDA-MB-231 breast cancer cells, with a $K_{\mathrm{d}}$ value of $962.74 \pm 113.51 \mathrm{nM}$. In addition to its higher binding affinity, the HER2-positive SKBR3 cell line also displayed higher number of binding sites $\left(B_{\max }=9.2 \times 10^{4}\right.$ receptors/cell, when compared with ERpositive MCF7 $\left(B_{\max }=4.5 \times 10^{4}\right.$ receptors $/$ cell $)$ and $\mathrm{T} 47 \mathrm{D}$ $\left(B_{\max }=4.2 \times 10^{4}\right.$ receptors/cell) cell lines.

To differentiate between the tightly cell-surface bound and cellular internalization of ${ }^{99 \mathrm{~m}} \mathrm{Tc}-\mathrm{HER} 2$ peptide, the cell-bound radioactivity was treated with acidic buffer (30) for $10 \mathrm{~min}$ at the end of the cell binding experiments. A fast and significant internalization was noticed for ${ }^{99} \mathrm{~m}$ Tc-HER2 since $19.89 \pm 5.34 \%$ of the cell-surface bound radiopeptide was internalized into 


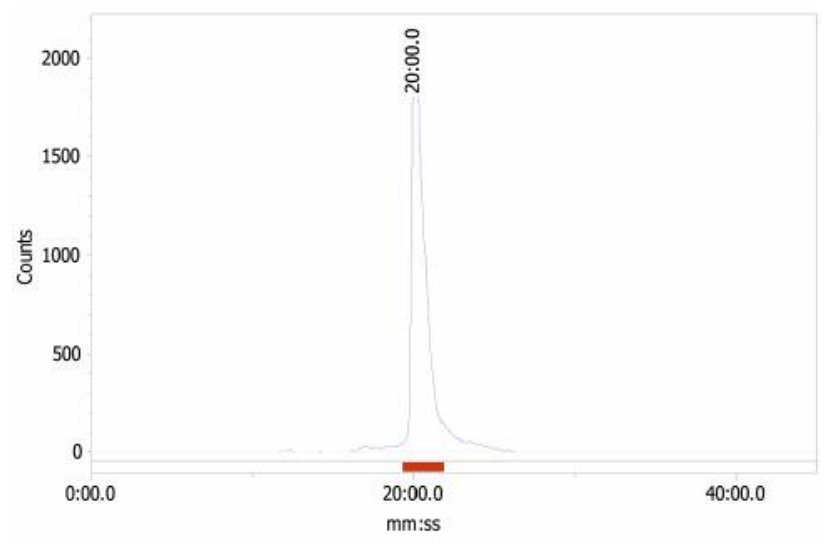

Figure 1. Radio-HPLC elution profile of ${ }^{99 m}$ Tc-HER2 peptide.

Table I. In vitro tumor cell binding characteristics and cellular internalization of ${ }^{99 m} T c-H E R 2$ peptide to SKBR3, MCF7, T47D human breast cancer cell lines.

\begin{tabular}{lrcc}
\hline Cell line & \multicolumn{1}{c}{$K_{\mathrm{d}}(\mathrm{nM})$} & $B_{\max }($ Sites/cell $)$ & $\%$ Internalization \\
\hline SKBR3 & $49.95 \pm 14.11$ & $92,450 \pm 6731$ & $19.89 \pm 5.34$ \\
MCF7 & $157.29 \pm 24.56$ & $45,815 \pm 5093$ & $12.15 \pm 3.19$ \\
T47D & $169.11 \pm 22.09$ & $42,100 \pm 5469$ & $11.86 \pm 2.82$ \\
\hline
\end{tabular}

SKBR3 cells after incubation in acidic buffer for $10 \mathrm{~min}$ at $37^{\circ} \mathrm{C}$. The internalization capacity of two ER-positive cell lines was found to be relatively lower than HER2-positive SKBR3 cell line as only $12.15 \pm 3.19 \%$ and $11.86 \pm 2.82 \%$ of the cell bound radioactivity was internalized into MCF7 and T47D cells, respectively (Table I). The results of cell-binding and internalization into various breast cancer cells demonstrate that in spite of the modifications in the peptide sequence, such as the introduction of a chelating sequence for radiolabeling and the addition of spacer function, the HER2-derived peptide retained its potency and held high affinity and specificity for breast cancer cell lines. This highlights the potential of ${ }^{99 \mathrm{~m}} \mathrm{Tc}$ HER2 for targeting human breast carcinomas.

In vivo biodistribution and tumor uptake studies. The findings of the biodistribution studies in normal $\mathrm{Balb} / \mathrm{c}$ mice at 1 and $4 \mathrm{~h}$ post-injection (p.i.) of ${ }^{99 \mathrm{~m}} \mathrm{Tc}$-HER2-derived peptide are summarized in Table II. The biodistribution of ${ }^{99 \mathrm{~m}} \mathrm{Tc}-\mathrm{HER} 2$ was first studied in healthy mice to determine normal tissue uptake patterns and clearance kinetics. The results show that the ${ }^{99 \mathrm{~m}} \mathrm{Tc}-\mathrm{HER} 2$ exhibited a rapid and efficient clearance from the blood as less than $2 \% \mathrm{ID} / \mathrm{g}$ was found in the blood at 1 and $4 \mathrm{~h} p . i$. The initial uptake taken by the liver was $3.74 \pm 0.70 \% \mathrm{ID} / \mathrm{g}$ at $1 \mathrm{~h}$ which decreased to $2.18 \pm 0.39 \% \mathrm{ID} / \mathrm{g}$ at $4 \mathrm{~h}$ p.i. The reasonable uptake of ${ }^{99 \mathrm{~m}} \mathrm{Tc}-$ HER2 peptide in the liver is possibly related to its modest

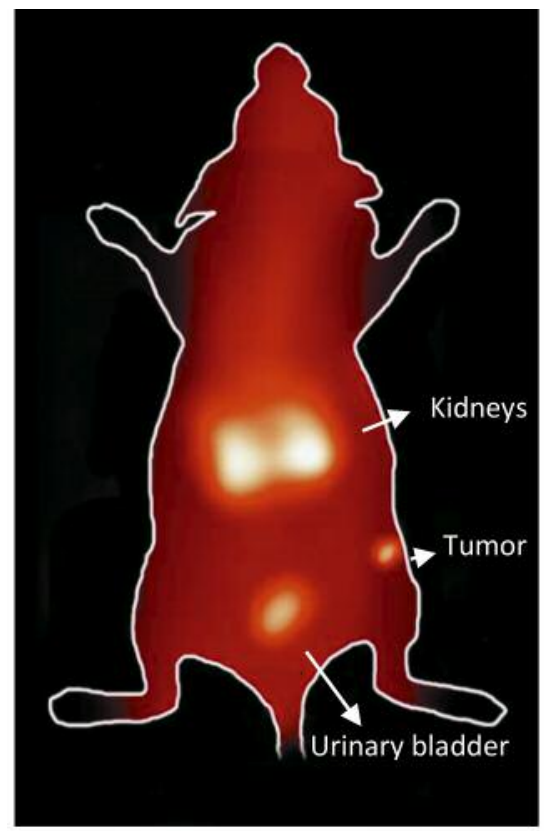

Figure 2. Gamma camera image of nude mouse model bearing SKBR3 tumor xenografts at $1 \mathrm{~h}$ after tail vein injection of $200 \mu \mathrm{Ci}$ of ${ }^{99 \mathrm{~m}} \mathrm{Tc}$-HER2 hybrid peptide.

lipophilicity ( $\log P=1.38 \pm 0.06)$. The uptake in the intestines (without the contents) was also found to be low (up to $2.41 \pm 0.42 \% \mathrm{ID} / \mathrm{g}$ ) both at 1 and $4 \mathrm{~h} p . i$. The ${ }^{99 \mathrm{~m}}$ Tc-HER 2 peptide revealed a moderate accumulation and retention in the kidneys $(5.96 \pm 1.02 \% \mathrm{ID} / \mathrm{g}$ at $1 \mathrm{~h}$ and, $4.85 \pm 0.86 \% \mathrm{ID} / \mathrm{g}$ at $4 \mathrm{~h} p . i$.). Though the observed kidney uptake is not very high but still a low uptake and retention by the kidneys is desired for diagnostic imaging in general and for radionuclide therapy in particular, because of potential kidney toxicity (31). A low to moderate uptake of radioactivity was observed in the stomach (range $=2.66-2.0$ $\% \mathrm{ID} / \mathrm{g}$ ) (Table II), indicating a low breakdown of the ${ }^{99 \mathrm{~m}} \mathrm{Tc}-$ HER2 complex in vivo and minimal reformation of free ${ }^{99} \mathrm{mcO}_{4}{ }^{-}$. Nonetheless, the high in vivo stability for ${ }^{99 \mathrm{~m}} \mathrm{Tc}-$ HER2 peptide correlates well with the high in vitro metabolic stability obtained in plasma. The uptake in the lungs was also low (below $2 \% \mathrm{ID} / \mathrm{g}$ both at 1 and $4 \mathrm{~h} p . i$.) indicating low colloidal particles formation by lungs. Urinary excretion values were estimated using the radioactivity associated with the excreted urine and bladder contents at the time of sacrifice. As anticipated, the clearance of the radiopeptide from the whole body occurred mainly through the urinary tract as up to $40.0 \pm 5.10 \%$ ID was found in the urine at $1 \mathrm{~h} \mathrm{p} . i$. In general, a rapid and efficient clearance of the radioactivity was observed from all the major organs, excluding the kidneys for ${ }^{99} \mathrm{~m}$ Tc-HER2-peptide. 
${ }^{99 \mathrm{~m}} \mathrm{Tc}-\mathrm{HER} 2$ peptide was further investigated in nude mice with HER2-positive SKBR3 tumor xenografts in order to determine its ability to target human breast cancer in vivo (Table III). Also, in nude mice, a fast and efficient clearance from the blood was observed as it was the case with Balb/c mice. A moderate uptake of $2.81 \pm 0.79 \% \mathrm{ID} / \mathrm{g}$ was found in the HER2-positive SKBR3 tumors as early as $1 \mathrm{~h} \mathrm{p.i.,} \mathrm{which} \mathrm{was}$ reduced to $1.22 \pm 0.25 \% \mathrm{ID} / \mathrm{g}$ at $4 \mathrm{~h} p . i$. (with $57 \%$ washout from the tumors over $4 \mathrm{~h}$ ). The uptake value in the tumor was always higher than the radioactivity found in the blood and muscle. Tumor-to-nontumor uptake ratios were also calculated and are shown in Table III. A trend of slight decreased tumorto-blood and tumor-to-muscle uptake ratios over time was obtained for ${ }^{99 \mathrm{~m}} \mathrm{Tc}-\mathrm{HER} 2$ peptide. The tumor-to-blood ratio obtained was 1.54 at 1 hand was dropped to 1.34 at $4 \mathrm{~h} p . i$. The tumor-to-muscle ratio was found to be 9.37 at $1 \mathrm{~h}$ and was reduced to 8.71 at $4 \mathrm{~h} p . i$. Uptake of radioactivity in the stomach was found to be lower (Table III) in nude mice than that in Balb/c mice. The kidneys showed the highest accumulation and retention of radioactivity (up to $10 \% \mathrm{ID} / \mathrm{g}$ ) and these values are about 2-times higher than the values found in the Balb/c mice. A high amount of radioactivity was excreted in the urine (up to $41 \%$ ID) whereas, the hepatobiliary excretion (liver + intestines) of this radiopeptide was below $15 \%$ ID. The results suggest that the good tumor targeting properties of this tumor-specific antigen peptide may make it useful for targeting human breast carcinomas.

In a receptor blocking study, administration of $100 \mu \mathrm{g}$ of HER 2 peptide 30 min before the injection of ${ }^{99 m}$ Tc-HER2 reduced its uptake from the tumors by approximately $62 \%$ $(1.07 \pm 0.24 \% \mathrm{ID} / \mathrm{g}$ blocked $v s .2 .81 \pm 0.79 \% \mathrm{ID} / \mathrm{g}$ unblocked, $p=0.02$ ), highlighting the specificity of the ${ }^{99 \mathrm{~m}}$ Tc-HER2derived peptide for HER2-positive SKBR3 breast cancer cell line. No marked influence of the blocking dose was observed in other major organs including lungs and kidneys suggesting nonspecific uptake of ${ }^{99 \mathrm{~m}} \mathrm{Tc}-\mathrm{HER} 2$ by these organs (data not shown).

Tumor targeting potential of ${ }^{99 \mathrm{~m}} \mathrm{Tc}-\mathrm{HER} 2$-derived peptide was also determined in mice with ER-positive MCF7 and T47D xenografts (Table IV). The ER-positive cell lines, MCF7 and T47D are classified as low HER2 expressing breast cancer cell lines $(2,10,29)$. Comparable tumor uptake and tissue biodistribution profiles were obtained between the nude mice models carrying ER-positive MCF7 and T47D breast cancer xenografts. The uptake of ${ }^{99 \mathrm{~m}} \mathrm{Tc}-\mathrm{HER} 2$ in the MCF7 and T47D tumors was $1.33 \pm 0.41 \% \mathrm{ID} / \mathrm{g}$ and $1.25 \pm 0.32$ at $1 \mathrm{~h}$ and $0.91 \pm 0.22 \% \mathrm{ID} / \mathrm{g}$ and $0.80 \pm 0.17 \% \mathrm{ID} / \mathrm{g}$ at $4 \mathrm{~h}$ p.i., respectively. These results demonstrate that the uptake by ER-positive tumors was about 2-fold lower than the uptake found in HER2-positive SKBR3 breast carcinoma. It is obvious from the biological evaluation that the ${ }^{99 \mathrm{~m}}$ Tc-HER2 displayed comparable tumor targeting characteristics in the species carrying two pharmacologically
Table II. In vivo tissue biodistribution studies of ${ }^{99 m} T c-H E R 2$ peptide in Balb/c mice at 1 and 4 h post-injection.

\begin{tabular}{lcr}
\hline & $1 \mathrm{~h}$ & \multicolumn{1}{c}{$4 \mathrm{~h}$} \\
\hline Blood & $1.94 \pm 0.42$ & $1.49 \pm 0.31$ \\
Lungs & $1.89 \pm 0.50$ & $1.21 \pm 0.23$ \\
Stomach & $2.66 \pm 0.67$ & $2.0 \pm 0.41$ \\
Pancreas & $1.04 \pm 0.15$ & $0.77 \pm 0.11$ \\
Intestines $^{\mathrm{a}}$ & $2.41 \pm 0.42$ & $1.18 \pm 0.19$ \\
Liver & $3.74 \pm 0.70$ & $2.18 \pm 0.39$ \\
Kidneys & $5.96 \pm 1.02$ & $4.85 \pm 0.86$ \\
Muscle & $0.63 \pm 0.10$ & $0.25 \pm 0.03$ \\
Urine \& bladder $^{\mathrm{b}}$ & $40.0 \pm 5.10$ & $37.0 \pm 4.71$ \\
\hline
\end{tabular}

Data are expressed as \% injected dose per gram of tissue/organ $(n=3-5$, mean values $\pm \mathrm{SD}$ ). ${ }^{\text {aPart }}$ of the intestines was measured without their contents. The radioactivity in the burine + bladder is expressed as \%injected dose per tissue.

Table III. In vivo tumor targeting studies of ${ }^{99 m}$ Tc-HER2 peptide in subcutaneous HER2-positive SKBR3 breast cancer xenografts mice models.

\begin{tabular}{lcc}
\hline & $1 \mathrm{~h}$ & $4 \mathrm{~h}$ \\
\hline Blood & $1.82 \pm 0.35$ & $0.91 \pm 0.15$ \\
Lungs & $2.75 \pm 0.41$ & $0.84 \pm 0.14$ \\
Stomach & $1.81 \pm 0.28$ & $1.05 \pm 0.14$ \\
Pancreas & $1.47 \pm 0.09$ & $0.67 \pm 0.06$ \\
Intestines $^{\mathrm{a}}$ & $1.73 \pm 0.32$ & $1.32 \pm 0.18$ \\
Liver $_{\text {Kidneys }}$ & $3.62 \pm 0.53$ & $2.28 \pm 0.46$ \\
Urine \& bladder & $9.94 \pm 2.11$ & $8.90 \pm 2.28$ \\
Muscle & $41.0 \pm 4.21$ & $37.0 \pm 5.10$ \\
Tumor & $0.30 \pm 0.06$ & $0.14 \pm 0.02$ \\
Ratios & $2.81 \pm 0.79$ & $1.22 \pm 0.25$ \\
$\quad$ Tumor/blood & & \\
Tumor/muscle & 1.54 & 1.34 \\
\hline
\end{tabular}

Data are expressed as \% injected dose per gram of tissue/organ $(n=3-5$, mean values $\pm \mathrm{SD}$ ). ${ }^{\text {aPart }}$ of the intestines was measured without their contents. The radioactivity in the ${ }^{b}$ urine + bladder is expressed as $\%$ injected dose per tissue.

different breast cancer cell lines highlighting the ability of ${ }^{99} \mathrm{~m}$ Tc-HER2-derived peptide to target not only HER2positive but also ER-positive breast cancer lines.

Furthermore, tumor-targeting behavior of ${ }^{99 \mathrm{~m}} \mathrm{Tc}-\mathrm{HER} 2$ was evaluated in nude mice carrying HER2-negative MDA-MB231 breast xenografts in order to further examine the tumor specificity of ${ }^{99 \mathrm{~m}} \mathrm{Tc}-\mathrm{HER} 2$ peptide by comparing the extent of tumor uptake in HER2-positive and HER2-negative cancer cell lines (Table IV). MDA-MB-231 is considered as HER2negative breast cancer cell line because of its low-expression for HER2 $(14,25)$. The tumor uptake value of $0.66 \pm 0.13 \%$ $\mathrm{ID} / \mathrm{g} v s .2 .81 \pm 0.79 \% \mathrm{ID} / \mathrm{g}(p=0.009)$ at $1 \mathrm{~h}$, and $0.31 \pm 0.10 \%$ 
Table IV. In vivo tumor-targeting properties of ${ }^{99 m}$ Tc-HER2 peptide in ER-positive MCF7 and T47D as well as in HER2-negative MDA-MB-231 breast cancer xenografts mice models.

\begin{tabular}{|c|c|c|c|c|c|c|}
\hline & \multicolumn{2}{|c|}{ MCF7 tumor } & \multicolumn{2}{|c|}{ T47D tumor } & \multicolumn{2}{|c|}{ MDA-MB-231 tumor } \\
\hline & $1 \mathrm{~h}$ & $4 \mathrm{~h}$ & $1 \mathrm{~h}$ & $4 \mathrm{~h}$ & $1 \mathrm{~h}$ & $4 \mathrm{~h}$ \\
\hline Blood & $2.12 \pm 0.36$ & $0.88 \pm 0.21$ & $2.51 \pm 0.12$ & $0.75 \pm 0.10$ & $2.40 \pm 0.31$ & $1.45 \pm 0.22$ \\
\hline Lungs & $2.57 \pm 0.10$ & $0.62 \pm 0.05$ & $3.53 \pm 0.10$ & $0.81 \pm 0.10$ & $2.05 \pm 0.23$ & $1.29 \pm 0.12$ \\
\hline Stomach & $1.42 \pm 0.16$ & $1.0 \pm 0.14$ & $1.64 \pm 0.30$ & $1.14 \pm 0.40$ & $4.59 \pm 0.48$ & $3.26 \pm 0.33$ \\
\hline Pancreas & $1.19 \pm 0.10$ & $0.79 \pm 0.06$ & $0.57 \pm 0.05$ & $0.35 \pm 0.03$ & $1.35 \pm 0.09$ & $0.95 \pm 0.07$ \\
\hline Intestines $^{\mathrm{a}}$ & $1.57 \pm 0.21$ & $1.22 \pm 0.14$ & $1.39 \pm 0.14$ & $0.90 \pm 0.12$ & $1.63 \pm 0.30$ & $1.13 \pm 0.15$ \\
\hline Liver & $3.62 \pm 0.17$ & $2.32 \pm 0.16$ & $3.12 \pm 0.15$ & $1.98 \pm 0.11$ & $4.22 \pm 0.18$ & $3.54 \pm 0.10$ \\
\hline Kidneys & $9.90 \pm 0.96$ & $8.74 \pm 1.07$ & $10.35 \pm 1.50$ & $8.36 \pm 0.36$ & $8.15 \pm 1.02$ & $4.96 \pm 0.95$ \\
\hline Urine \& bladder ${ }^{b}$ & $31.00 \pm 8.90$ & $25.00 \pm 4.16$ & $28.00 \pm 5.00$ & $23.00 \pm 3.17$ & $25.00 \pm 10.00$ & $24.00 \pm 9.510$ \\
\hline Muscle & $0.36 \pm 0.07$ & $0.15 \pm 0.03$ & $0.25 \pm 0.04$ & $0.13 \pm 0.02$ & $0.19 \pm 0.03$ & $0.10 \pm 0.02$ \\
\hline Tumor & $1.33 \pm 0.41$ & $0.91 \pm 0.22$ & $1.25 \pm 0.32$ & $0.80 \pm 0.17$ & $0.66 \pm 0.13$ & $0.31 \pm 0.10$ \\
\hline \multicolumn{7}{|l|}{ Ratios } \\
\hline Tumor/blood & - & 1.03 & - & 1.07 & - & - \\
\hline Tumor/muscle & 3.70 & 6.01 & 5.0 & 6.15 & 3.47 & 3.10 \\
\hline
\end{tabular}

Data are expressed as \% injected dose per gram of tissue/organ $\left(n=3-5\right.$, mean values \pm SD). ${ }^{\text {aPart }}$ of the intestines was measured without their contents. The radioactivity in the ${ }^{b}$ urine + bladder is expressed as $\%$ injected dose per tissue.

$\mathrm{ID} / \mathrm{g} v s .1 .22 \pm 0.25 \% \mathrm{ID} / \mathrm{g}(p=0.004)$ at $4 \mathrm{~h}$ was found in HER2-negative MDA-MB-231 versus HER2-positive SKBR3 tumors, respectively. These results validate the significant tumor uptake specificity by ${ }^{99 \mathrm{~m}}$ Tc-HER2 peptide for HER2positive SKBR3 cell line over HER2-negative MDA-MB-231 tumor xenografts. No marked difference in uptake patterns by the major organs was seen between the HER2-positive and HER2-negative tumor xenograft models (Table IV). In general, a fast clearance from all the organs and tissues was achieved, with the exception of the kidneys.

In vivo planar scintigraphic imaging. The tumor imaging property of ${ }^{99} \mathrm{~m}$ Tc-HER2-derived peptide was examined in a nude mouse bearing HER2-positive SKBR3 tumor xenografts at $1 \mathrm{~h}$ after the administration of radiopeptide. Although high accumulation of the radioactivity in the kidneys and urinary bladder is seen, the SKBR3 xenografted tumors are detectable in the image at $1 \mathrm{~h}$ p.i. (Figure 2), highlighting the potential use of tumor-antigen derived HER2 peptide for human breast cancer imaging. Immediately after the imaging, the mouse was sacrificed and quantitative tissue biodistribution was performed in order to confirm the findings of $\gamma$-imaging. The data from the in vivo imaging were in agreement with the in vivo biodistribution studies (Table III). Kidneys have been found to be the organs with the highest radioactivity uptake in the biodistribution and gamma image. So, to make ${ }^{99 \mathrm{~m}} \mathrm{Tc}-$ HER2-derived peptide more suitable for tumor imaging, besides the strategy to decrease kidney uptake, it is also important to increase the tumor uptake in future studies.

\section{Conclusion}

In the current study, we present a new ${ }^{99 m}$ Tc-labeled HER2targeted peptide with high metabolic stability and high affinity and specificity towards HER2-expressing tumor receptors, reflecting important properties of tumor-antigen derived peptides for molecular imaging of breast carcinoma. Further investigations will focus on the strategies to enhance tumor targeting characteristics and to reduce kidney retention of HER2-targeted peptide in order to make this emerging class of tumor-antigen peptides more suitable for breast cancer imaging.

\section{Acknowledgements}

The Authors would like to thank Ms. Celistina Macatuno for her help in animal experiments and Ms. Zakia Shinwari for the preparation of cells. Partial financial support from KACST is appreciated.

\section{References}

1 Mittendorf EA, Clifton GT, Holmes JP, Clive KS, Patil R, Benavides LC, Gates JD, Sears AK, Stojadinovic A, Ponniah S and Peoples GE: Clinical trial results of the HER-2/neu (E75) vaccine to prevent breast cancer recurrence in high-risk patients. Cancer 118: 2594-2602, 2012.

2 Sun M, Shi H, Liu C, Liu J, Liu X and Sun Y: Construction and evaluation of a novel humanized HER2-specific chimeric receptor. Breast Cancer Res 16: R61, 2014.

3 Hagimori M, Fuchigami Y and Kawakami S: Peptide-Based Cancer-Targeted DDS and Molecular Imaging. Chem Pharm Bull 65: 618-624, 2017. 
4 Mittendorf EA, Holmes JP, Ponniah S and Peoples GE: The E75 HER2/neu peptide vaccine. Cancer Immunol Immunother 57: 1511-1521, 2008.

5 Capala $\mathrm{J}$ and Bouchelouche K: Molecular imaging of HER2positive breast cancer - a step toward an individualized "Image and Treat" strategy. Curr Opin Oncol 22: 559-566, 2010.

6 Freudenberg JA, Wang Q, Katsumata M, Drebin J, Nagatomo I and Greene MI: The role of HER2 in early breast cancer metastasis and the origins of resistance to HER2-targeted therapies. Exp Mol Pathol 87: 1-11, 2009.

7 Kawamoto M, Horibe T, Kohno M and Kawakami K: HER2targeted hybrid peptide that blocks HER2 tyrosine kinase disintegrates cancer cell membrane and inhibits tumor growth in vivo. Mol Cancer Ther 12: 384-393, 2013.

8 Jiang H and Rugo HS: Human epidermal growth factor receptor 2 positive (HER2+) metastatic breast cancer: how the latest results are improving therapeutic options. Ther Adv Med Oncol 7: 321-339, 2015.

9 Ding H, Gangalum PR, Galstyan A, Fox I, Patil R, Hubbard P, Murali R, Julia Y and Holler LE: HER2-positive breast cancer targeting and treatment by a peptide-conjugated mini nanodrug. Nanomedicine: NBM 13: 631-639, 2017.

10 Asada S, Choi Y, Yamada M, Wang SC, Hung MC, Qin J and Uesugi M: External control of HER2 expression and cancer cell growth by targeting a Ras-linked coactivator. PNAS 99: 1274712752, 2002.

11 Mayer IA: Treatment of HER2-positive metastatic breast cancer following initial progression. Clin Breast Cancer 9: S50-S57, 2009.

12 Perik PJ, Lub-De Hooge MN, Gietema JA, van der Graaf WTA, de Korte A, Jonkman S, Kosterink JGW, van Veldhuisen DJ, Sleijfer DT, Jager PL and de Vries EGE: Indium-111-labeled trastuzumab scintigraphy in patients with human epidermal growth factor receptor 2-positive metastatic breast cancer. J Clin Oncol 24: 2276-2282, 2006.

13 Cai W, Niu G and Chen X: Multimodality imaging of the HERkinase axis in cancer. Eur J Nucl Med Mol Imaging 35: 186-208, 2008.

14 Li L, Wu Y, Wang Z, Jia B, Hu Z, Dong C and Wang F: SPECT/CT imaging of the novel HER2-targeted peptide probe $99 \mathrm{~m}$ Tc-HYNIC-H6F in breast cancer mouse models. J Nucl Med 58: 821-826, 2017.

15 Berezov A, Zhang HT, Greene MI and Murali R: Disabling ErbB Receptors with rationally designed exocyclic mimetics of antibodies: structure-function analysis. J Med Chem 44: 25652574, 2001.

16 Diderich P and Heinis C: Phage selection of bicyclic peptides binding HER2. Tetrahedron 70: 7733-7739, 2014.

17 Yang X, Wang Z, Xiang Z, Li D, Hu Z, Cui W, Geng L and Fang Q: Peptide probes derived from pertuzumab by molecular dynamics modeling for HER2 positive tumor imaging PLoS Comput Biol 13: e1005441, 2017.

18 Okarvi SM: Peptide-based radiopharmaceuticals and cytotoxic conjugates: Potential tools against cancer. Cancer Treat Rev 34: 13-26, 2008.
19 Karasseva NG, Glinsky VV, Chen NX, Komatireddy R and Quinn TP: Identification and characterization of peptides that bind human ErbB-2 selected from a bacteriophage display library. J Protein Chemistry 21: 287-296, 2002.

20 Kumar SR, Quinn TP and Deutscher SL: Evaluation of an ${ }^{111} \mathrm{In}-$ radiolabeled peptide as a targeting and imaging agent for ErbB2 receptor-expressing breast carcinomas. Clin Cancer Res 13: 6070-6079, 2007.

21 Anderson BW, Peoples GE, Murray JL, Gillogly MA, Gershenson DM and Ioannides CG: Peptide priming of cytolytic activity to HER-2 epitope $369-377$ in healthy individuals. Clin Cancer Res 6: 4192-4200, 2000.

22 Okarvi SM and Jammaz I: Synthesis and evaluation of a technetium-99m labeled cytotoxic bombesin peptide conjugate for targeting bombesin receptor-expressing tumors. Nucl Med Biol 37: 277-288, 2010.

23 Okarvi SM and Jammaz I: Preparation and evaluation of the tumor-specific antigen-derived synthetic mucin 1 peptide: A potential candidate for the targeting of breast carcinoma. Nucl Med Biol 43: 403-409, 2016.

24 Holliday DL and Speirs V: Choosing the right cell line for breast cancer research. Breast Cancer Research 13: 215-221, 2011.

25 Cai H, Singh AN, Sun X and Peng F: Synthesis and characterization of HER2-NLP peptide conjugates targeting circulating breast cancer cells: Cellular uptake and localization by fluorescent microscopic imaging. J Fluoresc 25: 13-117, 2015.

26 Guide for the Care and Use of Laboratory Animals. Washington, D.C.: National Academy Press, 1996.

27 Gebhart G, Flamen P, De Vries EGE, Jhaveri K and Wimana Z: Imaging diagnostic and therapeutic targets: human epidermal growth factor receptor 2. J Nucl Med 57: 81S-88S, 2016.

28 Yang X, Palasuberniam P, Kraus D and Chen B: Aminolevulinic acid-based tumor detection and therapy: molecular mechanisms and strategies for enhancement. Int J Mol Sci 16: 25865-25880, 2015.

29 Lattrich C, Juhasz-boess I, Ortmann O and Treeck O: Detection of an elevated HER2 expression in MCF-7 breast cancer cells overexpressing estrogen receptor $\beta 1$. Oncol Rep 19: 811-817, 2008.

30 Breeman WA, de Jong M, Erion JL, Bugaj JE, Srinivasan A and Bernard BF: Preclinical comparison of ${ }^{111}$ In-labeled DTPA- or DOTA-bombesin analogs for receptor targeted scintigraphy and radionuclide therapy. J Nucl Med 43: 1650-1656, 2002.

31 Rolleman EJ, Valkema R, de Jong M, Kooij PPM and Krenning EP: Safe and effective inhibition of renal uptake of radiolabelled octreotide by a combination of lysine and arginine. Eur J Nucl Med 30: 9-15, 2003.

Received January 29, 2018

Revised March 13, 2018

Accepted March 14, 2018 